\title{
Magnetic properties of vulcanized natural rubber nanocomposites as a function of the concentration, size and shape of the magnetic fillers
}

\author{
Felipe Silva Bellucci a, b, Fabricio César Lobato de Almeida ${ }^{\mathrm{c}}$, Marcos Augusto Lima Nobre ${ }^{\mathrm{d}}$, \\ Miguel Angel Rodríguez-Pérez ${ }^{\mathrm{e}}$, Amarildo Tabone Paschoalini a , Aldo Eloizo Job ${ }^{\mathrm{d}, *}$ \\ ${ }^{\text {a }}$ FEIS - Faculdade de Engenharia de Ilha Solteira, UNESP - Univ Estadual Paulista, CEP 15385-000, Ilha Solteira, SP, Brazil \\ b Ministério da Ciência, Tecnologia e Inovação - MCTI, CEP 70067-900, Brasília, DF, Brazil \\ ${ }^{\mathrm{c}}$ Department of Biosystem Engineering, UNESP - Univ Estadual Paulista, CEP 17602-496, Tupã, SP, Brazil \\ ${ }^{\mathrm{d}}$ FCT - Faculdade de Ciências e Tecnologia, UNESP - Univ Estadual Paulista, 19060-900, Presidente Prudente, SP, Brazil \\ e CellMat Laboratory, Condensed Matter Physics Department, University of Valladolid, 47011, Valladolid, Spain
}

\section{A R T I C L E I N F O}

\section{Article history:}

Received 8 May 2015

Received in revised form

30 August 2015

Accepted 16 September 2015

Available online 11 November 2015

\section{Keywords:}

A. Polymer-matrix composites (PMCs)

B. Magnetic properties

E. Compression moulding

\begin{abstract}
A B S T R A C T
Nickel-zinc ferrites as well as their nanocomposites formed by natural rubber are desirable because they take advantage of the thermal, mechanical and magnetic properties of each component. However, to date, the effect of the size, shape and concentration of the magnetic fillers on the magnetic properties of nanocomposite has not been studied in detail. In this report, we are presenting results about the influence of the geometric characteristic of fillers on the magnetic parameters of nanocomposites. Nickel -zinc ferrite nanopowders (NZF) with stoichiometry $\mathrm{Ni}_{0.5} \mathrm{Zn}_{0.5} \mathrm{Fe}_{2} \mathrm{O}_{4}$ were synthesized by a chemical route named the Modified Polyol Method (MPM) and magnetic nanocomposites were prepared with concentrations between 1 and $10 \mathrm{phr}$ of ferrite nanopowders by thermal compression and hot pressing. From TEM images of ferrite nanopowders aggregates and primary particles in the nanometric scale were identified with aspect ratio different from $1(r=a / b=0.99,0.55$ and 0.43). From VSM measurements and particle size, the NZF may be classified as a ferrimagnetic material in a paramagnetic state and the saturation magnetization $\left(\mathrm{M}_{\mathrm{S}}\right)$ was equal to $36.4 \mathrm{emu} / \mathrm{g}$. Performing VSM experiments with different degrees between the sample and the magnetic field, differences up to $9 \%$ were identified for the $M_{S}$ indicating a dependence of magnetic parameters on the concentration and shape of particles and aggregates. Magnetization versus time assays were carried out via VSM and two distinct relaxation times were achieved and associated with different populations of size and/or shape for the magnetic fillers. These results point to the possibility of modulation of the magnetic properties of vulcanized natural rubber composites by means of a suitable engineering process to control the concentration, size and shape of magnetic nanoparticles and agglomerates.
\end{abstract}

() 2015 Elsevier Ltd. All rights reserved.

\section{Introduction}

The nickel-zinc ferrites are isomorphic spinels to the $\mathrm{MgAl}_{2} \mathrm{O}_{4}$ mineral and they exhibit the molecular formula equal to $\left(\mathrm{Zn}_{x}^{2+} \mathrm{Fe}_{1-x}^{3+}\right)\left[\mathrm{Ni}_{x}^{2+} \mathrm{Fe}_{1+\chi}^{3+}\right] \mathrm{O}_{4}^{2-}$, where $\left(\mathrm{Zn}_{x}^{2+} \mathrm{Fe}_{1-x}^{3+}\right)$ are tetrahedral sites and $\left[\mathrm{Ni}_{x}^{2+} \mathrm{Fe}_{1+x}^{3+}\right]$ are octahedral sites. This kind of ferrite is a technologically attractive material, which is used commercially used as high-frequency ferrites for radio frequency coils and transformer and motor cores [1-3]. In the last few years, theses oxides have

\footnotetext{
* Corresponding author. Tel.: +55 1832295776.

E-mail address: job@fct.unesp.br (A.E. Job).
}

been applied in biomedical systems mainly as carriers for drug delivery, contrast agents for magnetic resonance imaging (MRI) and hyperthermia fluid applications [4,5]. The natural rubber from latex is a natural polymer (cis-1,4-polyisoprene), its monomer is the 2metil-1,3-butadieno $\left(\mathrm{C}_{5} \mathrm{H}_{8}\right)$ and the main source of latex is Hevea brasiliensis [6]. There are many kinds of syntactical rubbers such as styrene-butadiene rubber (SBR), butadiene rubber (BR), ethylene propylene diene monomer (EPDM), chloroprene Rubber (CR) and nitrile butadiene rubber (NBR), but none exhibit a better combination of good elasticity, low mechanical hysteresis, excellent dynamic properties, good tensile, tear strength and abrasive resistance than natural rubber [7,8]. For this reason, natural rubber is widely used in the tire and automotive industries. These unique 
properties and applications of nickel-zinc ferrites and natural rubber can be combined generating a nanocomposite material providing the best of both worlds $[9,10]$.

Nanocomposites formed by natural rubber and ceramic fillers are desirable, taking advantage of their thermal and mechanical properties from the elastomeric matrix and special function from the dispersed phase. Some examples are: (1) multiwalled carbon nanotubes were inserted in polymeric matrices producing significant mechanical improvements in the nanocomposites [11,12]; (2) barium strontium titanate embedded in a low-loss dielectric matrix that can be applied in microwave devices for wireless telecommunications [13]; (3) magnetic nanoparticles like nickel-zinc ferrite dispersed in vulcanized natural rubber forming rubber ferrite composites (RFCs) or magnetic polymer nanocomposites (MPNCs) that can be applied to various systems like electronic devices, integral circuits and magneto-optical media [14,15]; (4) flexible microwave absorbers based on nickel ferrite nanocomposites with a filler concentration of up120 phr were produced and they presented potential absorption at bands S and X [16]; (5) nickel-zinc ferrites and potassium strontium niobate were dispersed in vulcanized natural rubber forming magnetic and ferroelectric nanocomposites with low loss of mechanical properties [3]. In the last year, new preparation routes such as centrifugation of the latex and magnetic fillers formed in situ [17], thermal, dynamic mechanical, magnetic and dielectric properties have been the goal of investigation in the field of magnetic natural rubber nanocomposites $[18,19]$. However, reports on the influence of the size, shape, magnetic anisotropy and concentration of nickel-zinc ferrites on the magnetic properties of natural rubber nanocomposites are not abundant in scientific literature.

In this report, nickel-zinc ferrite nanopowders with magnetic properties and stoichiometry equal to $\mathrm{Ni}_{0.5} \mathrm{Zn}_{0.5} \mathrm{Fe}_{2} \mathrm{O}_{4}$ were synthesized by a chemical route named the Modified Polyol Method (MPM). Natural rubber nanocomposites with different concentrations of ferrite nanopowders were prepared by thermal compression and hot pressing. The influence of the size, shape and concentration of ferrite nanoparticles on the magnetic properties of natural rubber nanocomposites were identified and discussed.

\section{Materials and methods}

\subsection{Synthesis of the ferrite nanopowders and preparation of the magnetic nanocomposites (NR/NZF)}

The sample of nickel-zinc ferrite nanopowder with stoichiometry $\mathrm{Ni}_{0.5} \mathrm{Zn}_{0.5} \mathrm{Fe}_{2} \mathrm{O}_{4}$ (NZF) was synthesized by the Modified Polyol Method [20,21]. This chemical route is suitable for the synthesis of magnetic oxides because it permits an adequate control of shape, size and size distribution of the particles, parameters that influence their magnetic properties [22]. Starting reagents, chemical formula, molecular mass, purity and origin used were: nickel oxide $\left(\mathrm{Ni}_{2} \mathrm{O}_{3}, 165.39 \mathrm{~g} / \mathrm{mol}\right.$, analytical purity, VETEC), zinc oxide ( $\mathrm{ZnO}, 81.38 \mathrm{~g} / \mathrm{mol}$, analytical purity, VETEC), iron oxide $\left(\mathrm{Fe}_{2} \mathrm{O}_{3}\right.$, $159.69 \mathrm{~g} / \mathrm{mol}$, analytical purity, VETEC), ethylene glycol $\left(\mathrm{C}_{2} \mathrm{H}_{4}(\mathrm{OH})_{2}\right.$, $62.07 \mathrm{~g} / \mathrm{mol}$, analytical purity, FMAIA) and nitric acid $\left(\mathrm{HNO}_{3}\right.$, $63.01 \mathrm{~g} / \mathrm{mol}, 65 \%$, NUCLEAR). Reagents were weighed to the $\mathrm{Ni}_{0.5} \mathrm{Zn}_{0.5} \mathrm{Fe}_{2} \mathrm{O}_{4}$ stoichiometry and they were dissolved in nitric acid and ethylene glycol, in continuous agitation until they were completely dissolved. During magnetic stirring, the temperature was increased to $180{ }^{\circ} \mathrm{C}$. Afterwards, in a recipient, the material underwent a pre-calcination and a calcination, in a box type furnace.

The pre-calcination was carried out in two stages, under $\mathrm{N}_{2}$ flux of $500 \mathrm{~mL} / \mathrm{min}$. In the first stage, the temperature was gradually increased from room temperature with a heating rate equal to
$10{ }^{\circ} \mathrm{C} / \mathrm{min}$ up to $150{ }^{\circ} \mathrm{C}$ and a soaking time of $2 \mathrm{~h}$. In the second stage, at the same heating rate, the temperature was increased up to $300{ }^{\circ} \mathrm{C}$ for $1 \mathrm{~h}$. Cooling was performed at a natural furnace rate under $\mathrm{N}_{2}$ flux. The $\mathrm{N}_{2}$ flux is utilized to minimize the presence of any possible levels of oxygen in the furnace chamber derived from the air atmosphere. An oxygen level is undesirable but it is expected because the furnace is not hermetically closed. After this process, a fragile and reddish-brown powder was obtained, which was called precursor nanopowders. This powder was deagglomerated in an agate mortar and sieved at 325 meshes.

The Calcination of the precursor was carried out at $450{ }^{\circ} \mathrm{C}$ for $3 \mathrm{~h}$, under a dry air flux of $7 \mathrm{~L} / \mathrm{min}$. During the calcination, the heating and cooling rates were equal to $5{ }^{\circ} \mathrm{C} / \mathrm{min}$. The calcination temperature of $450{ }^{\circ} \mathrm{C}$ was selected to present an adequate combination of crystallinity, microstrain and saturation magnetization. More details about the method and other $\mathrm{Ni}_{0.5} \mathrm{Zn}_{0.5} \mathrm{Fe}_{2} \mathrm{O}_{4}$ synthesis can be provided by A. Daigle, (2011) and F. S. Bellucci (2012) [20,23].

Dry natural rubber was used for the preparation of the nanocomposites (cis-1,4-polyisoprene) of the commercial variety $\mathrm{CCB}$ (Crepe Claro Brasileiro - CCB), financed by the DLP Industria $e$ Comércio de Borracha e Artefatos ${ }^{\circledR}$ in the city of Poloni/SP. This rubber is obtained in processing plants by the coagulation of latex from the Hevea brasiliensis species, clones RRIM 600. Start reagents, chemical formula, purity and origin of the vulcanized system utilized were: zinc oxide $(\mathrm{ZnO}, 81.38 \mathrm{~g} / \mathrm{mol}$, analytical purity, VETEC), stearic acid $\left(\mathrm{CH}_{3}\left(\mathrm{CH}_{2}\right){ }_{16} \mathrm{COOH}, 284.48 \mathrm{~g} / \mathrm{mol}\right.$, analytical purity, VETEC), mercaptobenzotiazol $\left(\mathrm{S}_{2} \mathrm{NC}_{7} \mathrm{H}_{5}, 167.25 \mathrm{~g} / \mathrm{mol}\right.$, analytical purity, ORGANIC), sulphur $\left(\mathrm{S}_{8}, 256.52 \mathrm{~g} / \mathrm{mol}\right.$, analytical purity, VETEC). 100 phr of dry natural rubber was mixed with an activation system made up of 4 phr of zinc oxide and 3 phr of stearic acid and the ferrite nanoparticles calcined at $450{ }^{\circ} \mathrm{C}$ in concetrantion of $1,3,5,10,20$ or $50 \mathrm{phr}$ in an open mixing mill or a rubber mixer (Makintec, model $379 \mathrm{~m}$ ) at $40^{\circ} \mathrm{C}$. After $24 \mathrm{~h}$, the vulcanized agents were made up of $2 \mathrm{phr}$ of sulphur and then $1 \mathrm{phr}$ of 2-mercaptobenzotiazol was added to these mixtures also using the same mill for $10 \mathrm{~min}$ at $40^{\circ} \mathrm{C}$. The samples named NR/NZF $(1,3$, $5,10,20$ or $50 \mathrm{phr}$ ) were thermal compression molded by hot pressing under $2.5 \mathrm{MPa}$, at $150{ }^{\circ} \mathrm{C}$ for $8 \mathrm{~min}$ and $30 \mathrm{~s}$. The nanocomposites were conditioned, at least, $24 \mathrm{~h}$ prior to testing. Similar nanocomposites were produced with similar conditions by F. S. Bellucci et al. [24]. The vulcanized natural rubber and nanocomposites formulations are listed in Table 1 and the schematic representation of the general process of preparation is shown in Fig. 1.

\subsection{Characterization of the ferrite nanopowders and magnetic nanocomposites}

The structural characterization of ferrite nanopowders was carried out by infrared absorption spectroscopy (FTIR). The spectrophotometer FTIR used was a Bruker model Vector 22, in the region of $4000-400 \mathrm{~cm}^{-1}$, with an accuracy of $2 \mathrm{~cm}^{-1}$ and

Table 1

The vulcanized natural rubber and nanocomposites formulations.

\begin{tabular}{ll}
\hline Components & Quantity $\left(\mathrm{phr}^{\mathrm{a}}\right)$ \\
\hline Dry natural rubber & 100 \\
Zinc oxide & 4 \\
Stearic acid & 3 \\
Sulphur & 2 \\
2-Mercaptobenzothiazol & 1 \\
$\mathrm{Ni}_{0.5} \mathrm{Zn}_{0.5} \mathrm{Fe}_{2} \mathrm{O}_{4}$ & $0,1,3,5,10,20$ and 50 \\
\hline
\end{tabular}

${ }^{\mathrm{a}} \mathrm{phr}$ - Parts per hundred of rubber. 


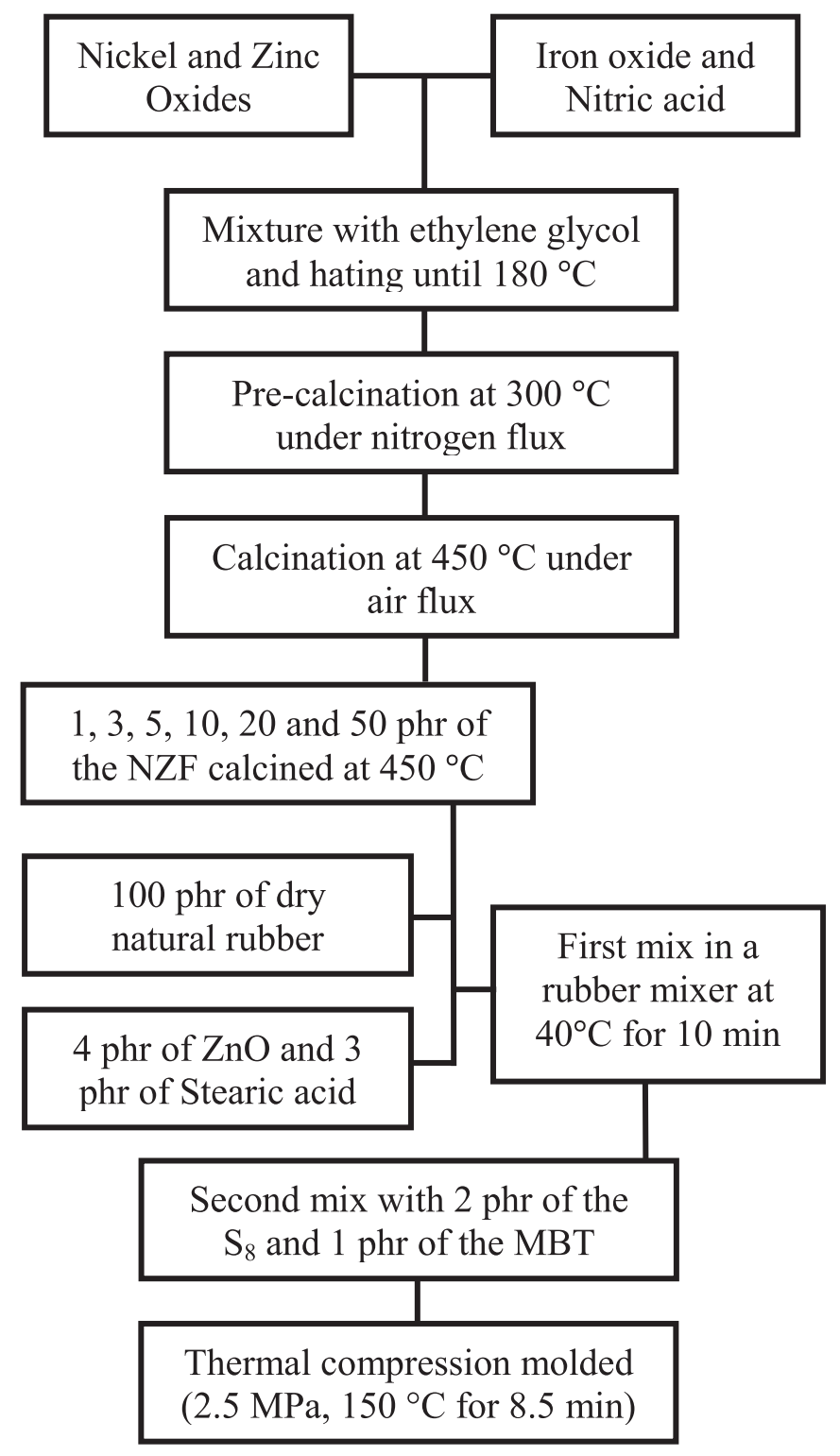

Fig. 1. Flow-chart for the fabrication of nanocrystalline nickel-zinc ferrite nanopowders by Modified Polyol Method and the preparation of the magnetic nanocomposites (NR/NZF).

128 scans. The samples were prepared by mixing the ferrite with $\mathrm{KBr}$, in a proportion of $1: 100$.

The morphological characterization of the ferrite nanopowders was carried out by Transmission Electron Microscopy (TEM) utilizing a JEOL microscopy, model JEM-1011 HR, with a field emission gun (FEG) system, tungsten filament and voltage acceleration between 40 and $100 \mathrm{kV}$. The ferrite nanopowders were dispersed in a volatile and polar solvent and the supernatant fraction of the dispersion was analyzed.

The morphological characterization of ferrite nanopowders, vulcanized natural rubber and nanocomposites was studied using a JEOL JSM-820 scanning electron microscope (SEM) and an energydispersive X-ray spectroscopy (EDX) using a EDAX Genesis. The nanocomposites measurements were performed directly on the fracture surface of the samples.

The magnetic characterization of the ferrite nanopowders, vulcanized natural rubber and nanocomposites was carried out by using a vibrating sample magnetometer (VSM), Lake Shore - model
7400 and 9600 , at room temperature and normalized by mass. The maximum external magnetic field was 15 kOe with the sample oscillating at $80 \mathrm{~Hz}$. VSM experiments were also carried out with degrees equal to $0,45,90$ e $135^{\circ}$ between the magnetic field $(\mathbf{H})$ and the surface normal vector (n) of the sample.

For isotropic magnetic composites in which the load was randomly dispersed in the matrix and without preferential orientation, the theoretical saturation magnetization of nanocomposites can be calculated using a simple mixture Equation (1).

$M_{S}($ composite $)=\frac{m_{2}}{m_{1}} M_{S}($ ferrite $)$

where $M_{\mathrm{S}}$ (composite) is the saturation magnetization of the composite, $M_{\mathrm{S}}$ (ferrite) is that of ferrite nanoparticles, $m_{1}$ is the mass of a given sample of nanocomposite, $m_{2}$ is the mass of ferrite nanoparticles in this sample and by assuming that all the other components in the nanocomposites are non-magnetic. Others kinds of mixture equations could be tested as, for example, the Equations (2) or (3), where $v$ is the volumetric fraction of each component and the " $n$ " is a coefficient whose value is between 1 and -1 , depending on the shape and anisotropy of the particles, kind of applied strain and others. However, for this kind of composite, the Equation (1) provides results which are more physically representative.

$M_{S}($ composite $)=\frac{M_{S}(\text { ferrite }) x M_{S}(\text { matrix })}{\left[\nu(\text { matrix }) x M_{S}(\text { ferrite })\right]+\left[\nu(\text { ferrite }) x M_{S}(\text { matrix })\right]}$

$$
\begin{aligned}
M_{S}(\text { composite })= & \nu(\text { ferrite }) x\left[M_{S}(\text { ferrite })\right]^{n} \\
& +\nu(\text { matrix }) x\left[M_{S}(\text { matrix })\right]^{n}
\end{aligned}
$$

It is possible to identify the physical phenomenon of magnetic after-effect, or magnetic viscosity, or Néel relaxation only for sufficiently fine ferromagnetic particles, as in our case [25]. In this case, it involves a whole of aligned uniaxial nanoparticles in the presence of a magnetic field. After a sufficiently long period of time, the magnetic field is switched off and, consequently, the thermal agitation starts to cause spontaneous misalignment of the nanoparticles and magnetization loss. Thus, the remanence magnetization as a function of time or the time-dependent of magnetic phenomena is governed by the Néel-Arrhenius theory [26], mathematically represented by Equation (4), while the superparamagnetic relaxation time $(\tau)$ is mathematically represented by Equation (5).

$M(t)=M_{0} \exp \left(\frac{-t}{\tau}\right)$

$\tau \approx\left(f_{0}\right)^{-1} \exp \left(\frac{-V K}{k T}\right)$

where $\mathrm{M}_{0}$ is the mean magnetization, " $\mathrm{t}$ " is the time after removal from the magnetic field, $f_{0}$ is the attempt frequency, $\mathrm{VK}$ is the value of the energy barrier, $\mathrm{k}$ is the Boltzmann constant and $\mathrm{T}$ is the temperature. In this case, the relaxation time is the time required for the remanence to decay to $1 / \mathrm{e}$ of $\mathrm{M}_{0}$, as well as being a term that varies with the volume and temperature of the nanoparticles $[27,28]$. 


\section{Results and discussions}

\subsection{Morphological and structural characterizations of the} nanoparticles and nanocomposites

Spectroscopic techniques as Energy-dispersive X-ray (EDX) and Fourier transform infrared spectroscopy (FTIR) are analytical techniques used for identifying specific bonds, elements and structures of the samples. Fig. 2 shows the infrared spectrum between 4000 and $400 \mathrm{~cm}^{-1}$ (a) and the EDX spectrum (b) of nickel-zinc ferrite nanopowders while Table 2 lists the infrared spectral frequencies of ferrite nanopowders. Inside Fig. 2(a) and (b), the representation of inverse spinel, tetrahedral (red) and octahedral (blue) sites. As can be seen in the infrared spectrum (Fig. 2(a) and Table 2), the characteristic superimposed bands associated to $\mathrm{O}-\mathrm{H}$ groups adsorbed on the surface of nanoparticles can be identified in the region of between 3500 and $2600 \mathrm{~cm}^{-1}$. The bands around 2344 and $2100 \mathrm{~cm}^{-1}$ are attributed to the stretch vibration of the $\mathrm{C}=0$ groups. All the vibration bands between 1700 and $900 \mathrm{~cm}^{-1}$, including the frequency at $1103 \mathrm{~cm}^{-1}$, can be correlated to the residual organic materials originating from the synthesis process, probably $\mathrm{C}-\mathrm{C}$ and $\mathrm{C}-\mathrm{O}$ bonds. In the region below $900 \mathrm{~cm}^{-1}$, the typical metal-oxygen bonds of the ceramic phases investigated can be found. In general, these bands overlap owing to the proximity of the maximum value of the bands. The absorption region between 500 and $600 \mathrm{~cm}^{-1}$ is attributed to the stretch vibration of metal-
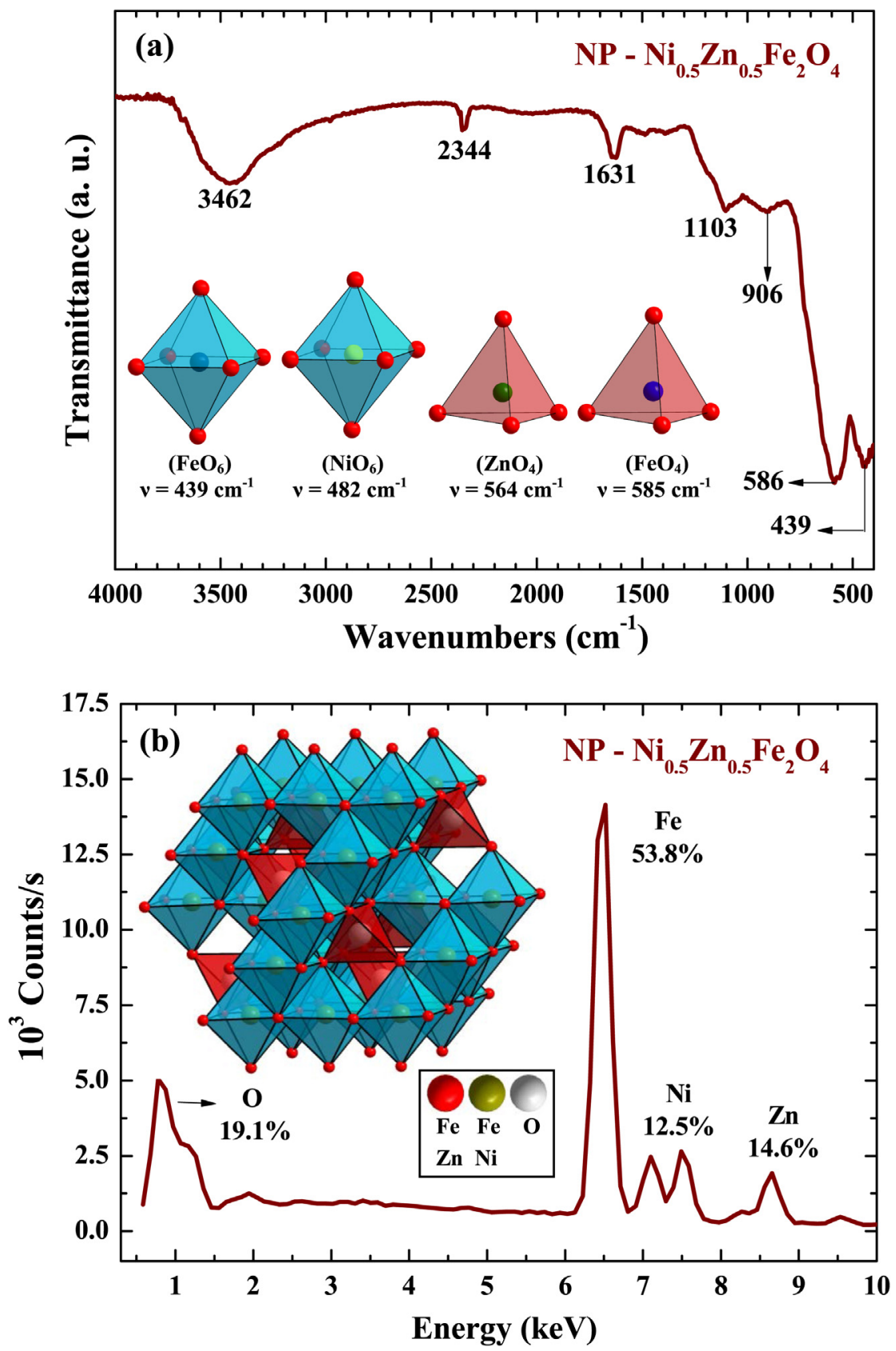

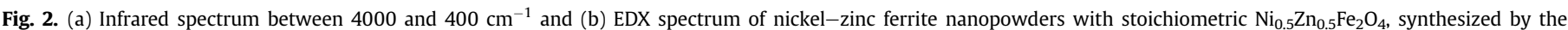

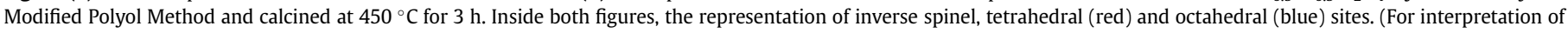
the references to colour in this figure legend, the reader is referred to the web version of this article.) 
Table 2

Infrared spectral frequencies between 4000 and $400 \mathrm{~cm}^{-1}$ for nickel-zinc ferrite nanopowders with stoichiometric $\mathrm{Ni}_{0.5} \mathrm{Zn}_{0.5} \mathrm{Fe}_{2} \mathrm{O}_{4}$, synthesized by the Modified Polyol Method and calcined at $450{ }^{\circ} \mathrm{C}$ during $3 \mathrm{~h}$.

\begin{tabular}{|c|c|c|}
\hline Component & Absorption band $\left(\mathrm{cm}^{-1}\right)$ & Attribution \\
\hline $\mathrm{Ni}_{0.5} \mathrm{Zn}_{0.5} \mathrm{Fe}_{2} \mathrm{O}_{4}$ nanopowders & $\begin{array}{l}439 \\
482 \\
564 \\
585\end{array}$ & $\begin{array}{l}\left(\mathrm{Fe}^{3+}-\mathrm{O}^{2-}\right) \text { in } \mathrm{FeO}_{6} \text { octahedral sites } \\
\left(\mathrm{Ni}^{2+}-\mathrm{O}^{2-}\right) \text { in } \mathrm{NiO}_{6} \text { octahedral sites } \\
\left(\mathrm{Zn}^{2+}-\mathrm{O}^{2-}\right) \text { in } \mathrm{ZnO}_{4} \text { tetrahedral sites } \\
\left(\mathrm{Fe}^{3+}-\mathrm{O}^{2-}\right) \text { in } \mathrm{FeO}_{4} \text { tetrahedral sites }\end{array}$ \\
\hline Residual organic material & $\begin{array}{l}900 \text { a } 915 \\
1300 \text { a } 1700 \\
2300 \text { a } 2500 \\
3300 \text { a } 3500\end{array}$ & $\begin{array}{l}(\mathrm{C}-\mathrm{C}),(\mathrm{C}-\mathrm{O}) \\
(\mathrm{C}=\mathrm{O}),(\mathrm{C}-\mathrm{O})_{\text {Absorbed }} \\
v(\mathrm{C}=\mathrm{O}) \\
v(\mathrm{O}-\mathrm{H})_{\text {Absorbed }}\end{array}$ \\
\hline
\end{tabular}

oxygen in the tetrahedral sites and the absorption region around $400 \mathrm{~cm}^{-1}$ is attributed to the stretch vibration of metal-oxygen in the octahedral sites [29]. The $\mathrm{Zn}^{2+}$ ions have a preference for the tetrahedral sites due to the possibility of making a covalent bond with the oxygen in the state of $\mathrm{sp}^{3}$ hybridization [27]. Therefore, it is expected that two bands at 564 and $585 \mathrm{~cm}^{-1}$ associated to the $\left(\mathrm{ZnO}_{4}\right)$ and $\left(\mathrm{FeO}_{4}\right)$ vibration in tetrahedral sites, respectively, are superimposed. The $\mathrm{Ni}^{2+}$ ions have a preference for the octahedral sites due their favourable adjustment to charge distribution of this ion in the crystal field of the octahedral site [27]. For these reasons, it is expected that two bands at 439 and $482 \mathrm{~cm}^{-1}$ associated to the $\left(\mathrm{FeO}_{6}\right)$ and $\left(\mathrm{NiO}_{6}\right)$ vibration in octahedral sites, respectively, are superimposed. The distribution of the different ions in the tetrahedral and octahedral sites can be modulated to improve the magnetic properties of the nanopowders changing, for example, the type of synthesis or its processing parameters. This profile of overlapping bands and these maximum values of bands are consistent with results reported elsewhere $[11,23,30]$. In the EDX analysis of the ferrite nanopowders [Fig. 2(b)], coherent amounts of O (19.1 wt\%), Fe (53.8 wt\%), Ni (12.5 wt\%) and Zn (14.6 wt\%) have been identified and these values are consistent with the theoretical/stoichiometry estimative for the nickel-zinc ferrite $\left(\mathrm{Ni}_{0.5} \mathrm{Zn}_{0.5} \mathrm{Fe}_{2} \mathrm{O}_{4}\right)$.

Because of the high spatial resolution, the transmission electron microscope (TEM) is a useful tool to determine the internal structure, size, shape and detailed crystallography of the grain and grain boundary. TEM images at room temperature of nickel-zinc ferrite nanopowders $\left(\mathrm{Ni}_{0.5} \mathrm{Zn}_{0.5} \mathrm{Fe}_{2} \mathrm{O}_{4}\right)$ with different magnifications, aggregate shapes and aspect ratio $(r=a / b)$ are shown in Fig. 3. The image (a) is a magnification of 10,000 times while images (b), (c) and (d) are magnifications of 600,000 times and they exhibit an aspect ratio equal to $0.99,0.55$ and 0.43 , respectively. Images (b), (c) and (d) were generated from specific areas of image (a). From TEM photographs of the NZF [Fig. 3(b), (c) and (d)], structures in the nanometric scale were identified and the geometry of primary particles is approximately spherical due to the growth mechanism, in this case, nucleation and coalescence to reach a minimum in the surface energy. The average particle size for the NZF is close to $10 \mathrm{~nm}$ while the size of the aggregates is around $100 \mathrm{~nm}$, with around 700 nanoparticles per cluster. The estimated value is for a spherical cluster considering a close-packing type and it is consistent with the complexity of the inverse spinel structure, 7 atoms/ cell in octahedral and tetrahedral sites). The average of grain size for the nickel-zinc ferrite is consistent with particle diameters reported elsewhere $[1,14,16]$. The formation of small aggregates of nanoparticles is typical for material processing by chemical routes [23]. However, it is important to note that nanoparticles forming the aggregate are weakly linked with each other through electrostatic interactions and the magnetic properties presented by the NZF nanoparticles can collaborate in the formation of larger clusters compared to clusters from a non-magnetic stage as described at [31]. In addition, the small agglomerates can assume diverse sizes, shapes and aspect ratio owing to different mass diffusion coefficients, thermal diffusivities, spatial limitations and others, see Fig. 3(a), (b) and (c). As a consequence, the small agglomerate can start showing, although weakly, anisotropy and presence of preferred magnetization directions. R P Cowburn reported how significant these changes of size, thickness and/or geometric shape (elliptical, triangular, square, pentagonal and circular geometries) of nanomagnets on the magnetic properties can be [22].

Scanning electron microscopy is based on high-energy electrons to generate a variety of signals at the surface of solid materials revealing information such as morphology, texture, chemical composition and crystalline structure of the sample. Fig. 4 shows SEM images and EDX spectra at room temperature of the fractured surface of vulcanized natural rubber (a) and magnetic nanocomposites with $1 \mathrm{phr}$ (b) and $20 \mathrm{phr}$ (c) of ferrite nanopowders. Inside each figure, there is a structural representation of the polymer chains and the ferrite nanoparticles. From Fig. 4, a satisfactory volumetric homogeneity can be observed which indicates an efficient mixing process and its appropriate quantities, types of cure system and vulcanization conditions for preparing nanocomposites. There are some white points on the fractured surface of the vulcanized natural rubber and three representative white points are indicated by arrows in Fig. 4(a). These points are associated with the vulcanization system, in particular, sub micrometric particles (>250 nm) of zinc and sulfur. In F. S. Bellucci et al. [23], Xray diffraction results are reported that associate these white points with zinc (JCPDS 80-0075 file) and sulfur (JCPDS 86-2249 file). As can be seen in Fig. 4 (b) and (c), it is possible to identify particles with nanometric dimensions $(\leq 75 \mathrm{~nm})$ and small agglomerates $(>75 \mathrm{~nm}$ and $\leq 250 \mathrm{~nm}$ ) and attribute them to the ceramic phase used. Sub-micrometric particles $(>250 \mathrm{~nm}$ ) can also be found and associated with particles of the vulcanization system and agglomerates of nanoparticles of greater dimensional magnitude. As expected, the volumetric density of points in the sample increases with the increment of the ceramic filler concentration. In the EDX spectra, peaks of $\mathrm{C}, \mathrm{O}, \mathrm{S}$, and $\mathrm{Zn}$ were identified and associated with the polymer chain and curing system. The percentage differences observed by EDX spectra for S and Zn elements in NR, NR/NZF-1 phr and NR/NZF-20phr samples refer only to the part of the sample investigated and the time of exposition of the sample to the X-ray. Low percentages of $\mathrm{Fe}, \mathrm{Ni}$ and $\mathrm{Zn}$ were found for samples of NR/NZF and assigned to nanoparticles NZF. The values obtained are in agreement with the amount estimated by stoichiometric calculations.

\subsection{Magnetic characterization of the nanoparticles and nanocomposites}

Vibrating sample magnetometry (VSM) is a very versatile and widely used technique to provide the main magnetic properties and relevant magnetic parameters of the sample with acceptable accuracy in a relatively fast way. The hysteresis loop between 

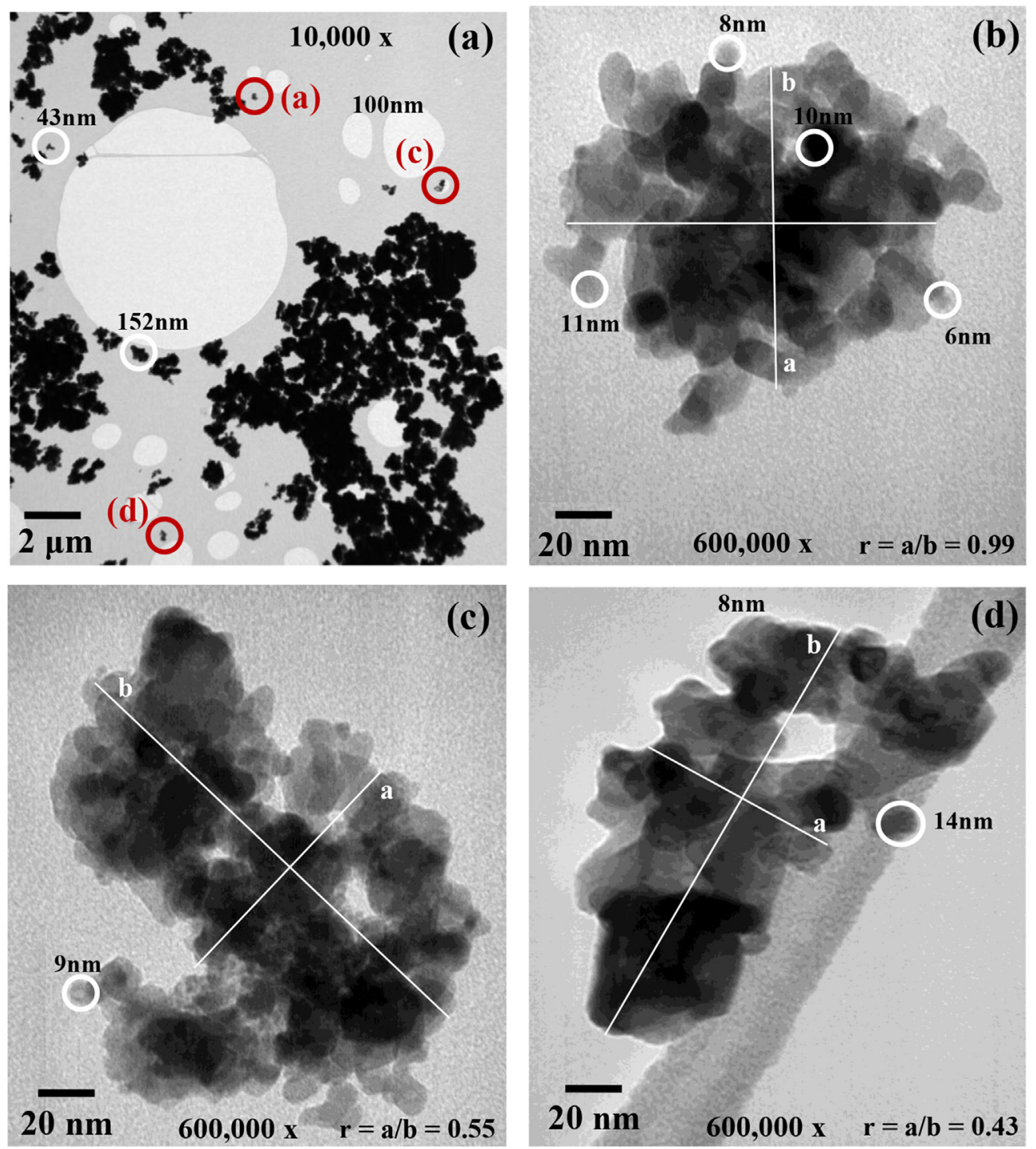

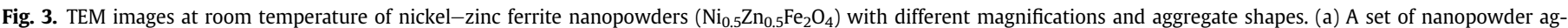

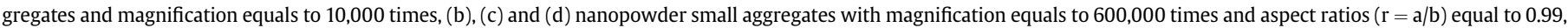
0.55 and 0.43 , respectively.

$\pm 15 \mathrm{kOe}$ at room temperature, details of the low magnetic field region between \pm 1 kOe and the main magnetic parameters like $\mathrm{M}_{\mathrm{S}}$, $\mathrm{M}_{\mathrm{R}}, \mathrm{H}_{\mathrm{C}}$ and $\mu_{\mathrm{i}}$ for nickel-zinc ferrite nanopowders are shown in Fig. 5. The hysteresis loop exhibits a characteristic profile of soft magnetic material at temperatures above the blocking temperature, which for this kind of material is about $50 \mathrm{~K}$ [32]. Soft magnetic materials or materials with low coercivity are systems used in technological applications whose magnetization/demagnetizing process should be easy, for example, in transformer and motor cores to minimize the energy dissipation with the alternating fields. In general, nickel-zinc ferrites are ferrimagnetic materials and, in this case, the NZF synthesized here can be classified as a ferrimagnetic material in a paramagnetic state due to the particle size and the characteristics of the hysteresis loop. It is possible to identify a small remanence and saturation magnetization in the hysteresis loop indicating the presence of a small population of particles outside the nanometer range and a population of small clusters tend to exhibit superparamagnetic and/or ferromagnetic behavior. If only individual nanoparticles were magnetically investigated, a hysteresis loop would be found similar to the classical curve for paramagnetic material. The evolution of magnetization of the sample as a function of the applied magnetic field would probably increase linearly without saturation and remanence effects.

Main magnetic parameters obtained from the hysteresis loop: the saturation magnetization $\left(\mathrm{M}_{\mathrm{S}}\right)$, coercive field $\left(\mathrm{H}_{\mathrm{C}}\right)$, remnant magnetization $\left(\mathrm{M}_{\mathrm{R}}\right)$ and initial magnetic permeability $\left(\mu_{\mathrm{i}}=(\mathrm{dB}(\mathrm{H}) /\right.$ $\mathrm{dH})_{\mathrm{H}=0}$ ) are equal to $36.4 \mathrm{emu} / \mathrm{g}, 95.6 \mathrm{Oe}, 4.4 \mathrm{emu} / \mathrm{g}$ and 0.03 , respectively. A low $\mathrm{M}_{\mathrm{S}}$ value was found for the ferrite nanopowders when compared with the sintered material (70.3 emu/g [30] and $56 \mathrm{emu} / \mathrm{g}$ [33]). This difference can be attributed to the nanometric size of the ferrite that exhibits only magnetic mono domains while sintered magnetic materials are of grain size outside the nanometer range and, in general, they exhibit the formation of magnetic multiple domain structures. This saturation magnetization value, $36.37 \mathrm{emu} / \mathrm{g}$, is about $77 \%$ of the magnetization of nickel nanoparticles with a particle size equal to $26 \mathrm{~nm}$ [34] and about $79 \%$ of the magnetization of magnetite $\left(\mathrm{Fe}_{3} \mathrm{O}_{4}\right)$ with a particle size equal to $19 \mathrm{~nm}$ [35]. It is suggested that these differences are related fundamentally to three factors: (i) the difference in the particle size, 

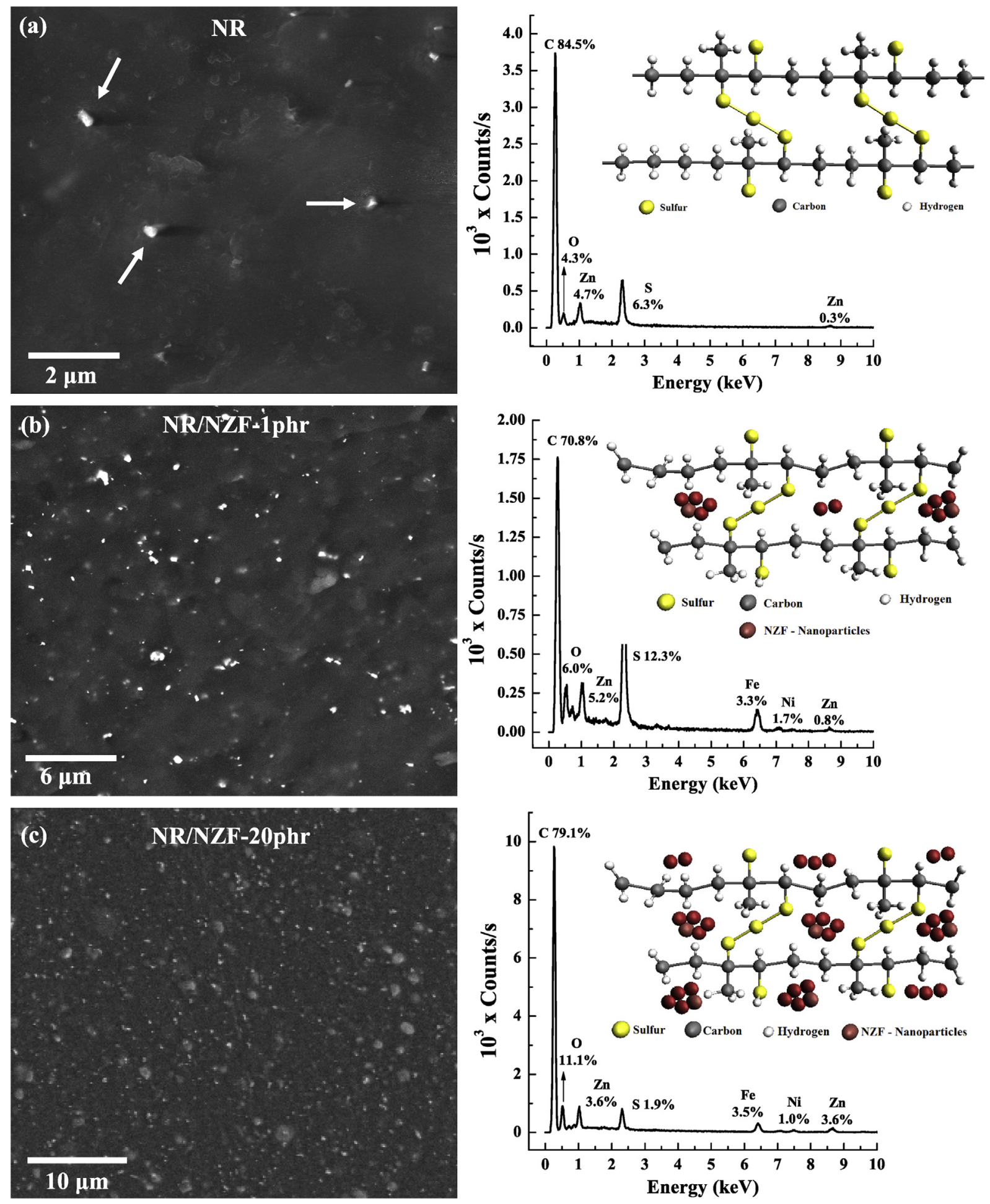

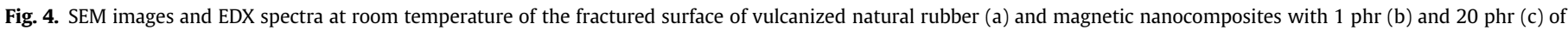
nickel-zinc ferrite nanopowders $\left(\mathrm{Ni}_{0.5} \mathrm{Zn}_{0.5} \mathrm{Fe}_{2} \mathrm{O}_{4}\right)$. On the right side of each figure, a structural representation of the polymer chains and the ferrite nanopowders.

(ii) different levels of complexity to the formation of each material, and (iii) different crystalline structures, for example, the NZF exhibits an inverse spinel structure, magnetite displays normal spinel structure and metallic nickel presents face-centered cubic structure. Different crystalline structures indicate different cation distributions in the material network and this fact has a direct influence on the magnetic properties of the sample.
Analysis of the remanence ratio $\left(M_{R} / M_{S}\right)$ : based on the hysteresis loop, a low remanence ratio $\left(\mathrm{M}_{\mathrm{R}} / \mathrm{M}_{\mathrm{S}}\right)$ was determined equal to 0.12 , typical of this hysteresis loop profile. This low value suggests that in the remanence state, the predominant dipolar interactions in these systems are negative which suppresses the remanence ratio below 0.5 . Negative dipolar interactions arise when the dipolar field of neighboring particles is acting in such a way as to destabilize the 


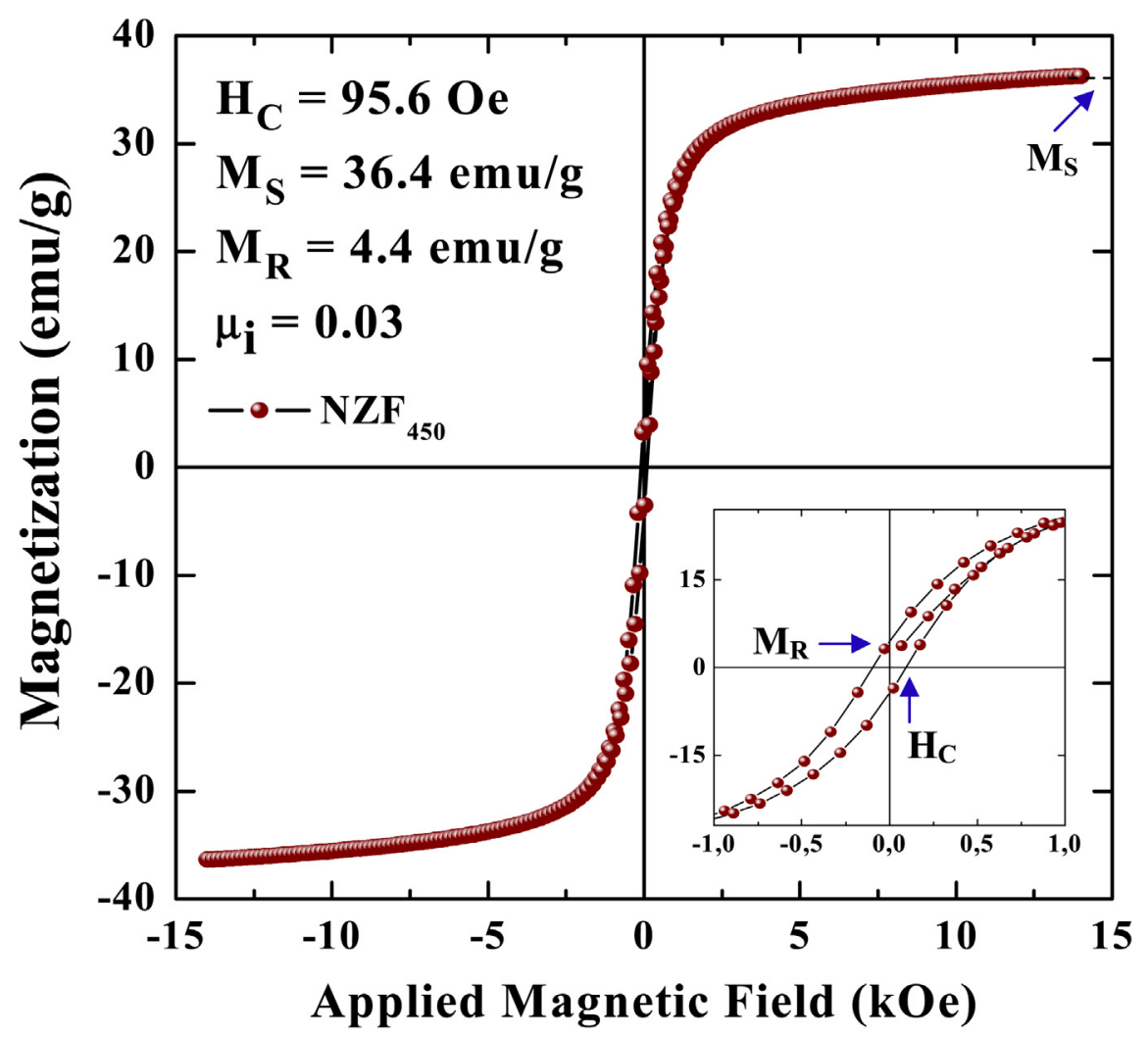

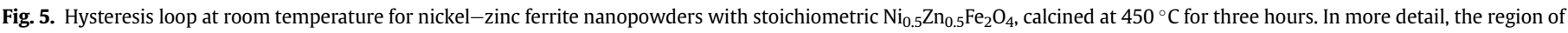
low magnetic fields and indications of $\mathrm{M}_{\mathrm{S}}, \mathrm{M}_{\mathrm{R}}, \mathrm{H}_{\mathrm{C}}$ and $\mu_{\mathrm{i}}$.

magnetization of a particle within the aggregate [27]. By extrapolating the analysis of results, it is expected that the evolution of the ferrite nanopowder magnetization depends on the analysis temperature: (i) a ferromagnetic behavior at low temperatures due to the loss of the magnetic order is not favoured at these temperatures, and (ii) a paramagnetic behavior at high temperatures because of the loss of magnetic order as a consequence of the intense thermal agitation in the material network.

Magnetic characterization of nanocomposites by VSM experiments can provide the main magnetic parameters and information about the interaction between matrix and fillers. Fig. 6 shows the hysteresis loops at room temperature and normalized by mass (a) and the details of low magnetic fields region (b) for vulcanized natural rubber (NR) and magnetic nanocomposites NR/NZF with concentrations between 1 and $50 \mathrm{phr}$ of ferrite nanoparticles. According to Fig. 6(a), the magnetic nanocomposites NR/NZF present a similar hysteresis loop to the ferrite nanoparticles calcined at $450{ }^{\circ} \mathrm{C}$ that are ferrimagnetics in a predominantly paramagnetic state. This fact indicates that the magnetic properties of the nanoparticles were preserved in the nanocomposites NR/NZF since the polymeric matrix of natural rubber is originally a non-magnetic material. As for the ferrite nanoparticles, the nanocomposites NR/ NZF have narrow hysteresis loops typical of soft magnetic materials which can cause low hysteresis losses. With the increase of the nanoparticles concentration in the magnetic nanocomposite NR/ $\mathrm{NZF}$, it is not possible to observe significant changes in a coercive field indicating a low interaction between the nanoparticles and the polymer matrix. This fact had already been expected because of the nanometric size of the fillers. If there was a significant increasing in the particle size, collaborative magnetic effects would be favored and significant changes in the coercive magnetic field could be observed. As can be seen in Table 3, a linear evolution of experimental and theoretical magnetization saturation, calculated by Equation (1), initial magnetic permeability and remanence magnetization has been identified with the increase of the nanoparticle concentration. The linear evolution presented by the magnetic parameters is due to the low chemical and physical interactions between nanoparticles/polymeric matrix and the only dependence on the magnetic material amount in the matrix, which is evidenced by the low percentage difference between the experimental and theoretical saturation magnetization. It should be emphasized that the inclusion of nanoparticles in the vulcanized natural rubber matrix causes low reduction of mechanical properties in NR/NZF, as reported by Ref. [3].

\subsection{Magnetic properties as a function of filler concentration and shape of agglomerates}

Magnetic particles in nanometric scale form a new technological area in which the size, thickness and geometric shape of these materials play a vital role in determining the magnetic properties. Fig. 7(a) shows an illustration of the magnetic experiment carried out by VSM with different degrees between the magnetic field $(\mathbf{H})$ and the surface normal vector (n) of the sample. Fig. 7(b) shows the hysteresis loops for the magnetic nanocomposite NR/NZF-1phr with degrees equal to $0,45,90$ e $135^{\circ}$ between $\mathbf{H}$ and $\mathbf{n}$ while Table 4 lists the values of $\mathrm{M}_{\mathrm{S}}$ for NR and NR/NZF with a concentration between 1 and $50 \mathrm{phr}$ carried out by VSM with different degrees between $\mathbf{H}$ and $\mathbf{n}$. From Fig. 7(b) and Table 4, it is possible to identify changes in the saturation magnetization for the magnetic nanocomposite NR/NZF a function of the degrees between $\mathbf{H}$ and $\mathbf{n}$ indicating a possible existence of magnetic anisotropy and/or preferred magnetization directions in the magnetic nanocomposites. We suggest that the source of the anisotropic process 


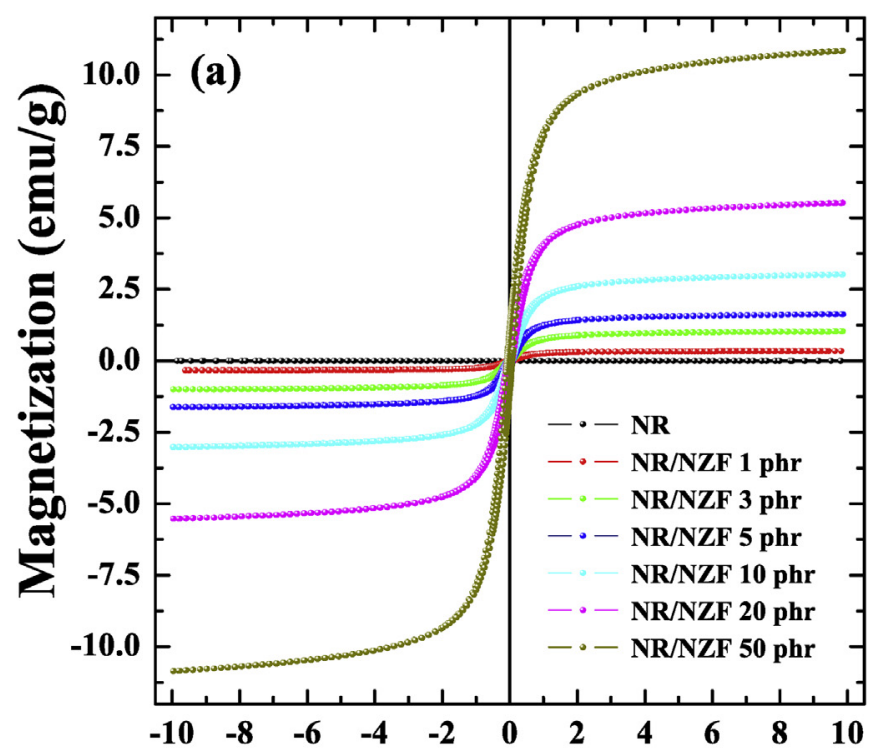

Applied Magnetic Field (kOe)

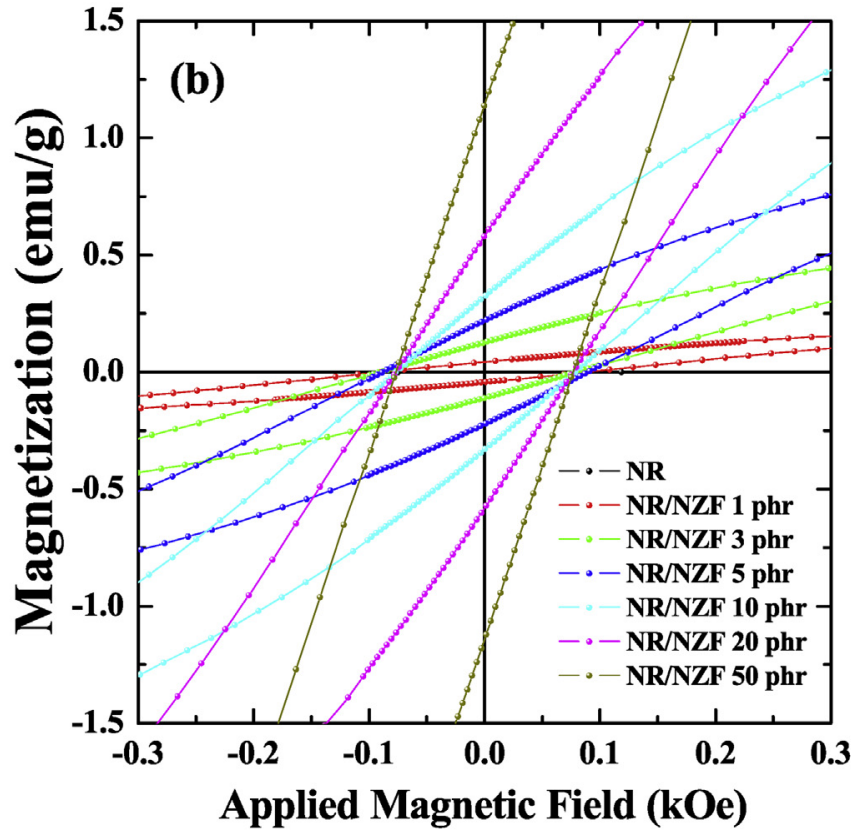

Fig. 6. Hysteresis loop performed at room temperature for vulcanized natural rubber (NR) and magnetic nanocomposites NR/NZF with concentration between 1 and $50 \mathrm{phr}$ of ferrite nanoparticles. (a) Magnetic field between $\pm 10 \mathrm{kOe}$ and (b) low magnetic field region between $\pm 0.3 \mathrm{kOe}$. (a)
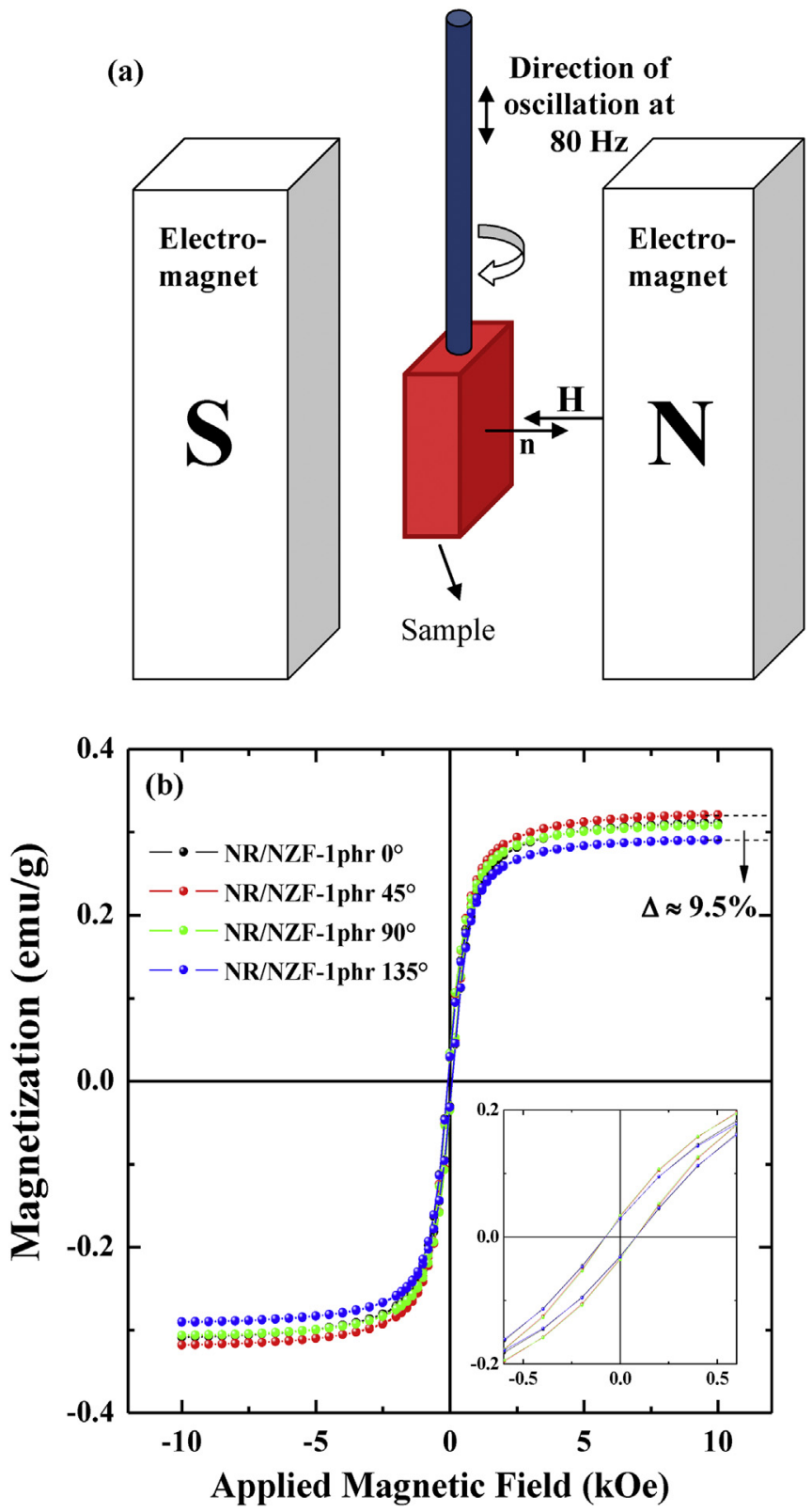

Fig. 7. (a) Illustration of the magnetic experiment carried out by VSM with different degrees between the magnetic field $(\mathbf{H})$ and the surface normal vector (n) of the sample. (b) Hysteresis loops for the magnetic nanocomposite NR/NZF-1phr with degrees equal to $0,45,90$ e $135^{\circ}$ between $\mathbf{H}$ and $\mathbf{n}$.

Table 3

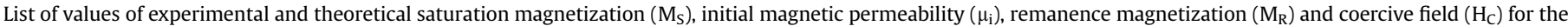
vulcanized natural rubber (NR) and magnetic nanocomposites NR/NZF with concentrations between 1 and 50 phr of ferrite nanoparticles.

\begin{tabular}{|c|c|c|c|c|c|c|}
\hline \multirow[t]{2}{*}{ Fillers (phr) } & \multicolumn{3}{|c|}{ Saturation magnetization (emu/g) } & \multirow[t]{2}{*}{ Initial magnetic permeability } & \multirow[t]{2}{*}{ Remanence magnetization (emu/g) } & \multirow[t]{2}{*}{ Coercive field (Oe) } \\
\hline & Experimental & Theoretical & $\Delta \%$ & & & \\
\hline NR & 0.005 & - & - & $-6.3 \times 10^{-8}$ & - & - \\
\hline 1 & 0.3 & 0.3 & 0.0 & $2.0 \times 10^{-5}$ & 0.0 & 98.5 \\
\hline 3 & 1.0 & 1.0 & 0.0 & $8.6 \times 10^{-4}$ & 0.1 & 79.7 \\
\hline 5 & 1.6 & 1.6 & 0.0 & $1.5 \times 10^{-3}$ & 0.2 & 89.1 \\
\hline 10 & 3.0 & 3.0 & 0.0 & $2.7 \times 10^{-3}$ & 0.3 & 76.4 \\
\hline 20 & 5.5 & 5.6 & +1.8 & $6.8 \times 10^{-3}$ & 0.6 & 77.3 \\
\hline 50 & 10.9 & 11.4 & +4.6 & $1.0 \times 10^{-2}$ & 1.2 & 77.3 \\
\hline
\end{tabular}


Table 4

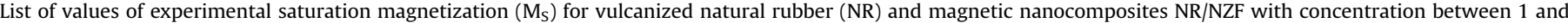
$50 \mathrm{phr}$ carried out by VSM with degrees equal to $0,45,90$ e $135^{\circ}$ between the magnetic field (H) and the surface normal vector (n) of the sample.

\begin{tabular}{|c|c|c|c|c|c|}
\hline \multirow[t]{2}{*}{ Samples } & \multicolumn{4}{|c|}{ Saturation magnetization $\left(\mathrm{M}_{\mathrm{S}}\right)$ with different degrees $(\mathrm{emu} / \mathrm{g})$} & \multirow[t]{2}{*}{ Maximum percentage difference (\%) } \\
\hline & $0^{\circ}$ & $45^{\circ}$ & $90^{\circ}$ & $135^{\circ}$ & \\
\hline NR & 0.005 & 0.005 & 0.005 & 0.005 & 0.0 \\
\hline NR/NZF-1phr & 0.32 & 0.31 & 0.31 & 0.29 & 9.4 \\
\hline NR/NZF-3phr & 0.89 & 0.91 & 0.88 & 0.84 & 7.7 \\
\hline NR/NZF-5phr & 1.46 & 1.45 & 1.42 & 1.38 & 5.6 \\
\hline NR/NZF-10phr & 2.96 & 2.99 & 2.87 & 2.76 & 5.5 \\
\hline NR/NZF-20phr & 5.51 & 5.57 & 5.48 & 5.27 & 5.4 \\
\hline NR/NZF-50phr & 9.90 & 9.91 & 9.76 & 9.39 & 5.2 \\
\hline
\end{tabular}

observed can be attributed to the existence of an aggregate formed by magnetic nanoparticles of a non-spherical shape, i.e. with an aspect ratio different from 1 [36], as can be seen in Fig. 2. The biggest difference identified between the maximum and minimum value for $\mathrm{M}_{\mathrm{S}}$ was equal to $9.4 \%$ for the nanocomposite NR/NZF-1phr. It is also observed that the maximum difference to the $M_{S}$ decreases exponentially with an increase of the nanoparticle concentration, as expected by K. Zhou et al. [13], since the paths traversed by the magnetic field in any region of the sample become more similar to each other with the increase of the nanoparticle concentration in the polymer matrix.

Magnetic assays as a function of time are primordial to determine the behavior of a material in the magnetization/demagnetization cycles and its residual magnetization. Fig. 8 shows the magnetization experiments at room temperature carried out by VSM as a function of time and normalized by the sample mass for the magnetic nanocomposites NR/NZF-1phr (a) and NR/NZF-20phr (b). The residual magnetization $\left(\mathrm{M}_{\mathrm{o}}\right)$ is equal to 0.17 and $0.24 \mathrm{emu} / \mathrm{g}$ for NR/NZF-1phr and NR/NZF-20phr, respectively, and it is proportional to the amount of magnetic material. The black points on the plot represent the experimental data and the continuous line represents the theoretical adjustment carried out via Equation (2). An excellent agreement between the experimental and theoretical curves was obtained by using two exponential factors and the Rsquat achieved were 0.98 and 0.94 for NR/NZF-1phr and NR/NZF$20 \mathrm{phr}$, respectively. The presence of two exponential factors to establish a better theoretical adjustment suggests mainly that there are two predominant relaxation phenomena associated with the population of size and/or shape for the magnetic component of the system. This observation is in agreement with the residual magnetic hysteresis noted in Fig. 4. The Relaxation times $(\tau)$, time required for the remanence to decay to $1 / \mathrm{e}$ of $\mathrm{M}_{0}$, have a coherent order of magnitude and their values are equal to 0.25 and $1.30 \mathrm{~h}$ (NR/NZF-1phr) and 0.37 and $1.43 \mathrm{~h}$ (NR/NZF-20phr). The value of $\tau$ depends on the competition between magnetic anisotropy energy and thermal energy, is proportional to the anisotropy constant and volume, and inversely proportional to temperature. Depending on the application desired, it is possible to modulate the $\tau$ and Mo by adjusting the processing parameters of the magnetic component of the system. The relaxation times and residual magnetizations for the magnetic nanocomposites are consistent with similar parameters reported elsewhere $[1,4]$.

\section{Conclusions}

Nickel-zinc ferrite nanopowders with stoichiometric $\mathrm{Ni}_{0.5} \mathrm{Zn}_{0.5}$ $\mathrm{Fe}_{2} \mathrm{O}_{4}$ and a particle size equal to about $15 \mathrm{~nm}$, were prepared by a chemical route named the Modified Polyol Method. Aggregates and primary particles in the nanometric scale and with an aspect ratio different from $1(r=a / b=0.99,0.55$ and 0.43$)$ were identified for the ferrite nanopowders via transmission electronic microscopy
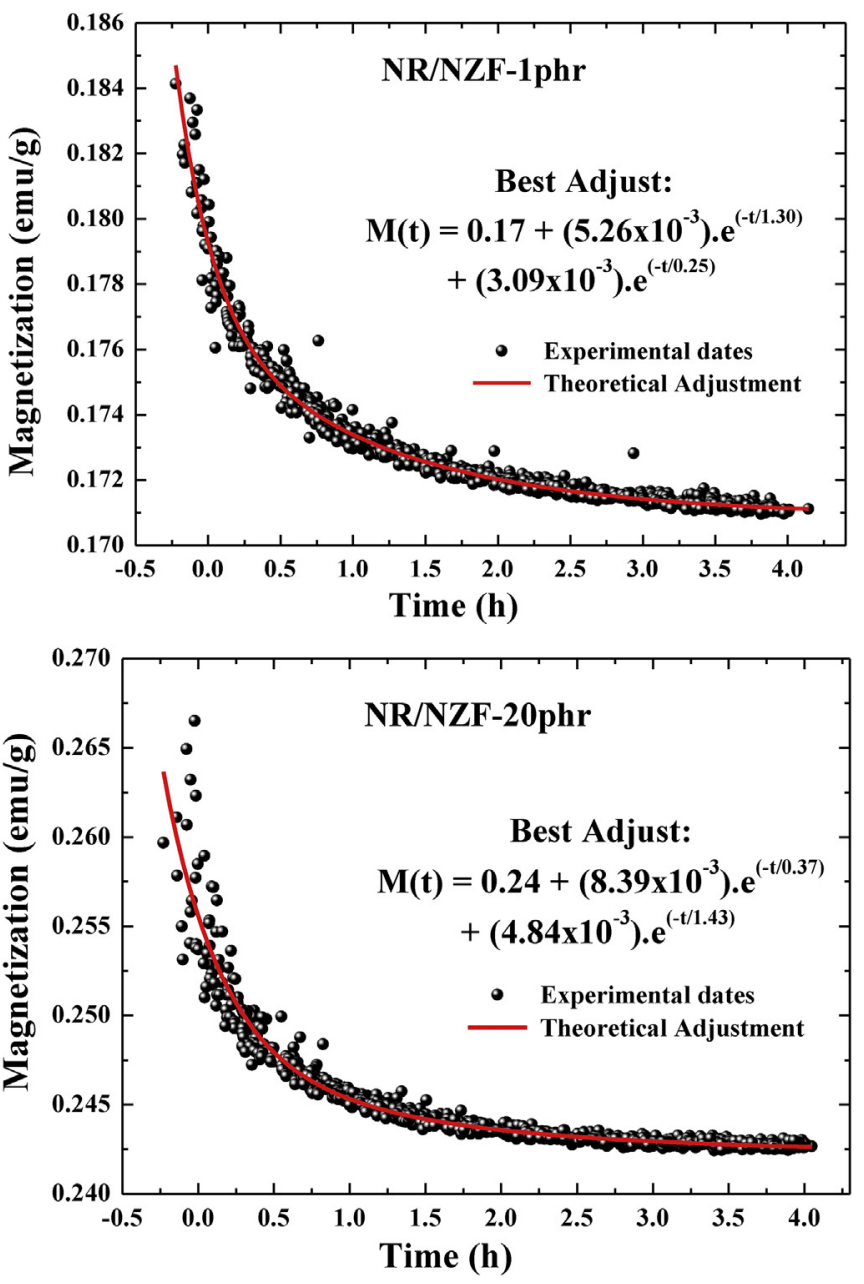

Fig. 8. Magnetization experiments at room temperature carried out by VSM as a function of time for the magnetic nanocomposites NR/NZF-1phr (a) and NR/NZF-20phr (b). The initial applied magnetic field was $10 \mathrm{kOe}$. The black points on the plot represent the experimental dates while the continuous red line represents the theoretical adjustment. Inside the graphics, the magnetization equation calculated. (For interpretation of the references to colour in this figure legend, the reader is referred to the web version of this article.)

(TEM). These nanoparticles were incorporated into the natural rubber matrix in a concentration between 1 and 50 phr forming magnetic natural rubber nanocomposites. By VSM measurement, differences up to $9 \%$ for the saturation magnetization of magnetic nanocomposites were found when different degrees between the sample and magnetic field were utilized indicating a dependence of magnetic parameters with the concentration and shape of particles and aggregates. From magnetization versus time experiments, two 
distinct relaxation times were achieved and associated with different populations of size or/and shape for the magnetic fillers. These findings indicate that the new applications for the nickel-zinc ferrites, natural rubber and magnetic nanocomposites can be achieved using the influence of geometric characteristic of fillers on the magnetic parameters of nanocomposites. In this way, economic and technological values are aggregates. In addition to that, the possibility of increasing or decreasing of the magnetic properties of vulcanized natural rubber composites through a suitable engineering process to control concentration, size and shape of magnetic nanoparticles and agglomerates was shown.

\section{Acknowledgements}

The authors acknowledge the Brazilian research agencies FAPESP ( $\left.n^{\circ} 2009 / 00523-8\right)$, CAPES ( ${ }^{\circ}$ BEX 5129/09-5 and $n^{\circ} 11208 /$ 13-9), CNPq ( ${ }^{\circ} 480377 / 2013-8,455323 / 2014-3$, 454843/2014-3 and $449999 / 2014-9)$ and FEPISA ( $\left.{ }^{\circ} 010 / 2014\right)$ for their financial support.

The author F. S. Bellucci is a post-doctorate researcher in FEISUNESP.

\section{References}

[1] Hee AC, Metselaar IHSC, Johan MR, Mehrali M. Preparation of nickel zinc ferrite by electrophoretic deposition. J Electrochem Soc 2012;159:E18.

[2] Corral-Flores V, Bueno-Baques D, Carrillo-Flores D, Matutes-Aquino JA. Enhanced magnetoelectric effect in core-shell particulate composites. J Appl Phys 2006;99:08J503.

[3] Bellucci FS, Budemberg ER, Nobre MAL, De Saja JA, Aroca RF, RodriguezPerez MA, et al. Mechanical properties of vulcanized natural rubber nanocomposites containing functional ceramic nanoparticles. Sci Adv Mater 2013;5:637-46.

[4] Lee SW, Kim CS. Superparamagnetic properties Ni-Zn ferrite for nano-bio fusion applications. J Magn Magn Mater 2006;304:e418-20.

[5] Sharifi I, Shokrollahi H, Amiri S. Ferrite-based magnetic nanofluids used in hyperthermia applications. J Magn Magn Mater 2012;324:903-15.

[6] Gilbert NE, Dodds KS, Subramanian S. Progress of breeding investigation with Hevea brasiliensis, V. Analysis of data from earlier crosses. J Rubber Res Inst Malays 1973;3:365.

[7] Job AE, Cabrera FC, Salmazo LO, Rodriguez-Perez MA, Gil AL, de Siqueira AF, et al. Chapter 26. Applications of natural rubber composites and nanocomposites. In: Thomas S, Chan C, Pothen L, Joy J, Maria H, Org, editors. RSC polymer chemistry series. 1 ed., vol. 2. Royal Society of Chemistry; 2013. p. $742-71$.

[8] Hofmann W. Rubber technology handbook. Hanser Gardner Publications; 2000. 651p.

[9] Flaifel MH, Ahmad SH, Abdullah MH, Al-Asbahi Bandar Ali. NiZn ferrite filled thermoplastic natural rubber nanocomposites: effect of low temperature on their magnetic behaviour. Cryogenics 2012;52:523.

[10] Job AE, Bellucci FS, Cabrera FC, de Siqueira AF, Budemberg RE, Salmazo LO. Chapter 15. Magnetic filler-reinforced natural rubber macro- and nanocomposites. In: Thomas S, Chan C, Pothen L, Joy J, Maria H, Org, editors. RSC polymer chemistry series. 1 ed, vol. 2. Royal Society of Chemistry; 2013. p. $432-66$.

[11] Cadek M, Coleman JN, Barron V, Hedicke K, Blau WJ. Morphological and mechanical properties of carbon-nanotube-reinforced semicrystalline and amorphous polymer composites. Appl Phys Lett 2002;81:5123.

[12] Xu Q, Yao Y, Ma Z, Xia Z. Measurement of interfacial energy and friction between carbon nanotubes and polymer matrix by a micro-pullout test. Sci Adv Mater 2012;4:888.
[13] Zhou K, Boggs SA, Ramprasad R, Aindow M, Erkey C, Alpay SP. Dielectric response and tunability of a dielectric-paraelectric composite. Appl Phys Lett 2008;93:102908.

[14] Calebrese C, Hui L, Schadler LS, Keith J. A review on the importance of nanocomposite processing to enhance electrical insulation. IEEE Trans Dielectr Electr Insul 2011;18:938.

[15] Khimi SR, Pickering KL. Comparison of dynamic properties of magnetorheological elastomers with existing antivibration rubbers. Compos Part B 2015;83:175-83. http://dx.doi.org/10.1016/j.compositesb.2015.08.033.

[16] Sunny V, Kurian P, Mohanan P, Joy PA, Anantharaman MR. A flexible microwave absorber based on nickel ferrite nanocomposite. J Alloys Comp 2010;489:297.

[17] Gallardo PS, Flores LLD, Rodríguez AL, Rivera MAH, Castañon CS, Morales MEO. Natural rubber/magnetite nanocomposites obtained from centrifuged latex and by in situ reactive process. Adv Sci Lett 2013;19:3564-7.

[18] Flaifel MH, Ahmad SH, Hassan A, Bahri S, Tarawneh MA, Yu LJ. Thermal conductivity and dynamic mechanical analysis of NiZn ferrite nanoparticles filled thermoplastic natural rubber nanocomposite. Compos Part B 2013;52: 334-9.

[19] Malas A, Das CK. Effect of graphene oxide on the physical, mechanical and thermo-mechanical properties of neoprene and chlorosulfonated polyethylene vulcanizates. Compos Part B 2015;79:639-48.

[20] Daigle A, Modest J, Geiler AL, Gillette S, Chen Y, Geiler M, et al. Structure, morphology and magnetic properties of $\mathrm{Mg}(\mathrm{x}) \mathrm{Zn}(1-\mathrm{x}) \mathrm{Fe}_{2} \mathrm{O}_{4}$ ferrites prepared by polyol and aqueous co-precipitation methods: a low-toxicity alternative to $\mathrm{Ni}(\mathrm{x}) \mathrm{Zn}(1-\mathrm{x}) \mathrm{Fe}_{2} \mathrm{O}_{4}$ ferrites. Nanotechnol 2011;22. 305708.

[21] Feldman C. Polyol-mediated synthesis of nanoscale functional materials. Solid State Sci 2005;7:868.

[22] Cowburn RP. Property variation with shape in magnetic nanoelements. J Phys D Appl Phys 2000;33:R1-16.

[23] Bellucci FS, Salmazo LO, Budemberg ER, da Silva MR, Rodríguez-Pérez MA Nobre MAL, et al. Preparation and structural characterization of vulcanized natural rubber nanocomposites containing nickel-zinc ferrite nanopowders. J Nanosci Nanotechnol 2012;12:2691.

[24] F. S. Bellucci, L. O. Salmazo, E. R. Budemberg, M. A. L. Nobre, A. E. Job. Método de produção de nanocompósitos funcionais e produtos obtidos. Patent filed in INPI on March/2012, under $\mathrm{n}^{\circ}$ BR102012005278-4, and with international application filed on March/2013 under ${ }^{\circ}$ PCT/BR 2013/000063.

[25] Coffey WT, Kalmykov YP. Thermal fluctuations of magnetic nanoparticles: fifty years after Brown. J Appl Phys 2012;112:12.

[26] Néel L. Propriétés magnétiques des ferrites; ferrimagnétisme et antiferromagnétisme. Ann Phys 1948;3:137-98.

[27] Liu Y, Sellmyer DJ, Shindo D. Handbook of advanced magnetic materials: nanostructural effects. Tsinghua University Press, Springer; 2006.

[28] Tumanski S. Handbook of magnetic measurement. CRC Press,Taylor \& Francis Group; 2011.

[29] El-Sayed AM. Influence of zinc content on some properties of $\mathrm{Ni}-\mathrm{Zn}$ ferrites. Ceram Int 2002;28:363.

[30] Wu H, Ting TH, Liu CI, Yang CC, Hsu JS. Electromagnetic and microwave

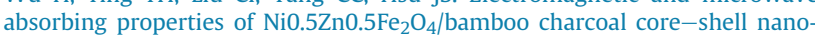
composites. Comp Sci Technol 2008;68:132.

[31] Jamal EMA, Joy PA, Kurian P, Anantharaman MR. On the magnetic, mechanical and rheological properties of rubber-nickel nanocomposites. Polym Bull 2010;64:907.

[32] Morrison SA, Cahill CL, Calvin S, Harris VG. Magnetic and structural properties of nickel zinc ferrite nanoparticles synthesized at room temperature. J Appl Phys 2004;95:6392.

[33] Sepelák V, Tkáová K, Boldyrev VV, Wibmann S, Becker KD. Mechanically induced cation redistribution in $\mathrm{ZnFe}_{2} \mathrm{O}_{4}$ and its thermal stability. Phys B Condens Matter 1997;234:617.

[34] Jamal EMA, Joy PA, Kurian P, Anantharaman MR. Synthesis of nickel-rubber nanocomposites and evaluation of their dielectric properties. Mater. Sci Eng, B 2009;24:156.

[35] Woo K, Hong J, Choi S, Lee HW, Ahn JP, Kim CS, et al. Easy synthesis and magnetic properties of iron oxide nanoparticles. Chem Mater 2004:2814:16.

[36] Lu HM, Zheng WT, Jiang Q. Saturation magnetization of ferromagnetic and ferrimagnetic nanocrystals at room temperature. J Phys D Appl Phys 2007;40: 320. 